\title{
O perfil das publicações sobre condições de trabalho e saúde dos professores: um aporte para (re) pensar a literatura
}

\section{Profile of publications on teacher's working conditions and health: a contribution to (re)think the literature}

\author{
Jefferson Peixoto da Silva ${ }^{a}$ \\ (iD) https://orcid.org/0000-0002-7293-4895 \\ E-mail: jefferson.silvaœfundacentro.gov.br

\section{Frida Marina Fischer ${ }^{b}$} \\ (iD) https://orcid.org/0000-0001-9403-6300 \\ E-mail: fischer.fridaळgmail.com
}

aFundação Jorge Duprat Figueiredo de Segurança e Medicina do Trabalho. Serviço de Apoio à Diretoria de Pesquisa. São Paulo, SP, Brasil.

buniversidade de São Paulo. Faculdade de Saúde Pública. Departamento de Saúde Ambiental. São Paulo, SP, Brasil.

\section{Correspondência}

Jefferson Peixoto da Silva

Fundação Jorge Duprat Figueiredo de Segurança e Medicina do Trabalho. Serviço de Apoio à Diretoria de Pesquisa. Rua Capote Valente, 710, São Paulo, SP, Brasil. CEP: 05409-002.

\section{Resumo}

O objetivo deste artigo é apresentar os resultados de uma pesquisa bibliográfica, realizada nas bases de dados da Biblioteca Virtual em Saúde (BVS) e na Scientific Electronic Library Online (SciELO), sobre as condições de trabalho e saúde de professores. O escopo da pesquisa abrangeu um período de 20 anos (1997-2017) e revelou um conjunto de 175 estudos elegíveis que, por sua natureza e volume, foram organizados em categorias e subcategorias, compondo o seguinte perfil: (1) Problemas de saúde; (2) Condições de trabalho e saúde; (3) Qualidade de vida; (4) Trabalho, carreira e fundamentos da ação docente. Os resultados mostram que houve interesse crescente pelo assunto nos últimos anos e que despontaram estudos sobre qualidade de vida dos professores a partir de 2006. Apesar do grande número de estudos sobre trabalho e saúde docente, a área educacional tem dedicado pouca atenção à saúde dos professores, demonstrando que o tema requer uma abordagem multidisciplinar.

Palavras-chave: Professores; Trabalho; Saúde do Trabalhador. 
This paper discusses the results of a literature review carried out at the Biblioteca Virtual em Saúde (BVS) and Scientific Electronic Library Online (SciELO) databases, covering a period of 20 years (1997-2017), about teachers' working conditions and health. Our search returned a set of 175 eligible studies that were grouped, according to their characteristics and size samples, into the following categories: (1) Health disorders; (2) Working conditions and health; (3) Quality of life; (4) Work, career and fundamentals of teaching. Results show a growing interest on the topic in recent years, and especially regarding teachers' quality of life as of 2006. Despite the vast number of studies on teachers' work and health, the educational field has spared little attention to its professionals' health, showing the need for a multidisciplinary approach on the topic.

Keywords: Teachers; Work; Occupational Health.
Os professores constituem uma categoria profissional de fundamental importância para a sociedade e seu desenvolvimento, conforme reconhece a Organização Internacional do Trabalho (Ilo/Unesco, 2016). Nos últimos anos, a produção acadêmica dedicada ao assunto vem apontando para um cenário de intensificação e precarização das condições de trabalho desses profissionais (Assunção; Oliveira, 2009; Guerreiro et al., 2016), com repercussões negativas sobre a saúde (Delcor et al., 2004; Gasparini et al., 2005) e, consequentemente, sobre a vida (Silva; Fischer, 2020).

No quadro de doenças típicas da profissão, figuram principalmente os distúrbios mentais e comportamentais; os distúrbios da voz; os transtornos musculoesqueléticos; e os problemas cardiológicos (Vedovato; Monteiro, 2008), com o agravante da alta incidência que os transtornos mentais e comportamentais têm apresentado (Farber, 1984; Paparelli, 2009; Cortez et al., 2017).

A gravidade do problema coloca em questão as reais condições para o exercício da prática docente, ou seja, as condições que os professores encontram para realizarem seu trabalho de relevância pública e social. Assim, torna-se cada vez mais oportuno dedicar atenção ao problema e, nesse sentido, os esforços de mapeamento e análise da produção científica sobre o assunto ganham importância, principalmente diante do aumento do número de publicações que vem sendo identificado (Araújo et al., 2019).

Ao analisamos a produção científica, publicada em um período de 20 anos (1997-2017), sobre trabalho e saúde de professores da educação básica, identificamos certos padrões que, codificados tematicamente, revelaram um perfil. Considerando, sobretudo, que as pesquisas que trazem resultados semelhantes (Leite; Souza, 2011; Cortez et al., 2017) abordaram períodos de análise distintos (1996-2007; 2003-2016, respectivamente), utilizaram bases de dados diversas, focalizaram estudos de diferentes tipos, lidaram com um volume relativamente menor de achados e os classificaram sob formas particulares, entendemos que este trabalho fornece um novo aporte para apreender, analisar e discutir a literatura concernente ao assunto. 


\section{Métodos}

Foi realizado um levantamento bibliográfico nas bases de dados Biblioteca Virtual de Saúde (BVS) e Scientific Electronic Library Online (SciELO). O objetivo foi encontrar artigos dedicados ao tema trabalho e saúde dos professores que demonstrassem identificação e/ou interesse para a perspectiva do campo teórico da saúde do trabalhador (Mendes; Dias, 1991). Assim, a estratégia de busca visou garantir a máxima abrangência possível e empregou os termos: "professor", "docente", "saúde do professor e docente", "cotidiano professor e docente" e "profissionais da educação". Além disso, utilizou-se o recurso de truncamento, de modo que ao empregarmos a expressão "professo\$”" (ou “professo*”), a busca retornasse todos os resultados derivados da raiz do truncamento, a saber: professor, professora, professores, professoras. 0 mesmo se aplica ao termo "docent\$”: docente, docentes.

Conforme as características de cada plataforma, houve especificidades no ajuste da estratégia. $\mathrm{Na}$ BVS, por exemplo, não utilizamos a expressão "saúde" (do professor ou do docente). Por se tratar de uma base de pesquisa em saúde, fazê-lo seria redundante. No entanto, ela nos permitiu aplicar filtros como "saúde do trabalhador", "condições de trabalho", "doenças profissionais" e outros que auxiliaram a delimitar a busca.

Na base SciELO a expressão "saúde" (do professor, do docente e dos profissionais da educação) foi utilizada, visto não ser uma plataforma específica do campo da saúde. Ao mesmo tempo, os periódicos de outras áreas nela indexados (como educação e psicologia educacional) foram considerados de interesse, já que um dos objetivos era verificar se os estudos do campo educacional tinham como foco o problema do adoecimento dos docentes.

Pelas razões supramencionadas - de ampla abrangência pretendida - todos os resultados que preencheram os critérios de elegibilidade foram considerados, independente do periódico. Tais critérios consistiram em: (1) ser pesquisa realizada com professores do ensino fundamental e médio; (2) ter sua publicação no período dos últimos 20 anos (1997-2017); e (3) ter como foco professores brasileiros. Foram incluídos artigos em português, espanhol e inglês.

Foram excluídos os trabalhos voltados a professores universitários, a professores da educação infantil, além dos estudos em duplicidade. Tal processo se deu em três etapas. Durante a análise preliminar, aplicou-se filtros e recursos de delimitação disponíveis nas plataformas (especialmente na BVS), a fim de restringir a dimensão dos achados aos artigos de interesse. Entre os filtros, utilizou-se, por exemplo, "saúde do trabalhador", "condições de trabalho" e "doenças profissionais". Entre os recursos de delimitação, empregou-se "and not professores universitários e do ensino superior" e "and not educação infantil”. Por termos identificado que, entre os estudos voltados a professores universitários, a maior parte investigava docentes da área de enfermagem, incluímos também “and not enfermagem".

Feito isso, realizou-se uma triagem para excluir títulos que demonstravam incompatibilidade com os parâmetros delimitados. No total, 394 artigos foram excluídos nessa etapa. Por fim, os resumos dos trabalhos resultantes $(n=232)$ foram verificados (em alguns casos, o próprio conteúdo precisou ser consultado para eliminação de dúvidas) de modo a descartar aqueles que não apresentaram correspondência. Para análise dos artigos elegíveis $(n=175)$, aplicou-se o procedimento de codificação temática (Gibbs, 2009), tendo o software Mendeley como suporte.

Em termos da concepção inicial do levantamento, tomamos como referência o trabalho de revisão de literatura de Leite e Souza (2011) que, elaborado como parte do projeto "condições de trabalho e suas repercussões na saúde dos professores de Educação Básica no Brasil” (Ferreira, 2010), analisou 65 obras publicadas de 1997 a $2006,{ }^{1}$ entre teses $(n=10)$, dissertações $(n=51)$ e livros $(n=04)$.

1 Embora publicada em 2011, a referida revisão (Leite; Souza, 2011) analisou trabalhos publicados até o ano de 2006. 
Em nosso levantamento, priorizamos artigos e atualizamos o período da análise, ampliando-o até o ano de 2017 (1997-2017). A fim de evitar duplicidade ou sobreposição, atentamos para não incorporar resultados já contemplados pela revisão supramencionada (Leite; Souza, 2011), tarefa facilitada pelo fato de termos analisado produções distintas. Empreendemos também o esforço de identificar os artigos que decorreram de teses e dissertações contempladas entre as 65 obras do estudo em questão e chegamos a 9 correspondências. Mantivemos tais artigos entre os nossos resultados por se tratar de publicações de tipos distintos.

A pesquisa realizada para este trabalho foi aprovada pelo Comitê de Ética em Pesquisa da Faculdade de Saúde Pública of Universidade de São Paulo, no. 1,553,835, CAAE 54839516.1.oooo.5421.

\section{Resultados}

Aplicados os filtros, os recursos de delimitação e as exclusões, os resultados revelaram um total de 175 estudos elegíveis: BVS ( $n=101)$ e SciELO $(n=74)$. A análise do material conduziu a quatro categorias principais de estudos. 0 Gráfico 1 apresenta essas categorias $^{2}$ e a distribuição dos achados em termos percentuais. A Tabela 1, por sua vez, demonstra a composição das quatro categorias principais - suas subcategorias - em números absolutos e percentuais.

\section{Gráfico I - Categorias principais das publicações}

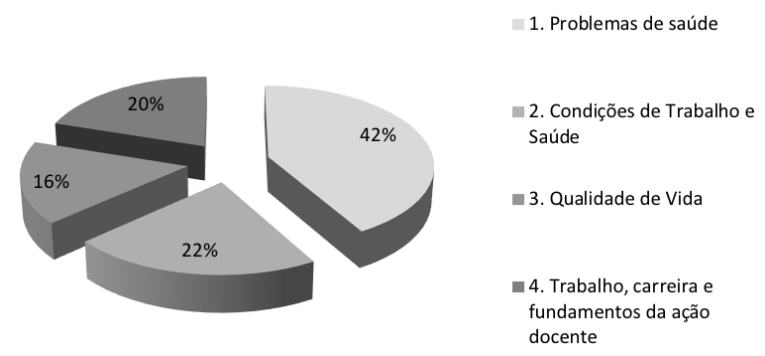

Fonte: Elaboração própria com referência aos dados do levantamento junto à BVS e SCIELO

\section{Categoria I. Estudos sobre problemas de saúde}

A primeira categoria contemplou, em suas subcategorias, os estudos dedicados a analisar problemas de saúde específicos (como os relativos a distúrbios da voz e a transtornos mentais e comportamentais, por exemplo, conforme Tabela 1) que acometem os professores. De modo geral, esses dois tipos de estudos estão vinculados aos campos da fonoaudiologia e da saúde mental, respectivamente.

Embora as pesquisas sobre os outros componentes dessa categoria (transtornos musculoesqueléticos/ osteomusculares, saúde cardiovascular e saúde ocular) tenham sido encontradas em número pouco expressivo, tal categoria comporta, assim como as demais, espaço para relacionar e agrupar (entre as subcategorias) novas investigações que venham a ser realizadas a respeito de problemas de saúde específicos entre os professores.

Como característica metodológica central, os artigos desta seção se definiram pela perspectiva predominantemente quantitativa das análises, com exceção de alguns estudos do campo da psicologia dedicados à saúde mental dos professores que se utilizaram de métodos qualitativos.

\section{Categoria 2. Estudos sobre condições de trabalho e saúde dos professores}

A segunda categoria constituiu um grupo mais complexo de se classificar, tendo em vista a diversidade de estudos vinculados à temática. Mesmo ligados em torno de um núcleo comum, eles demonstraram compartilhar um elo de natureza nem sempre fácil de identificar, já que tal vínculo por vezes se apresentou de modo pouco explícito à primeira vista. A análise de suas características principais, contudo, revelou que os estudos estavam voltados a fenômenos cuja manifestação remetem diretamente às condições de trabalho em sua relação com a saúde, conforme Tabela 1.

A despeito da variedade apresentada nos estudos vinculados a essa categoria, eles demonstraram uma

2 As categorias estão representadas conforme a ordem em que foram sendo constituídas a partir dos achados e, como tal, refletem, em primeiro plano, o levantamento realizado junto à BVS. A categoria $n^{\circ} 4$ foi constituída apenas após o levantamento junto à base SciELO. 
consistente correspondência com o tema central em questão. Assim, pesquisas dedicadas a investigar as condições de trabalho e saúde dos professores propriamente ditas (ou condições de trabalho e saúde em geral), constituíram a maior parte dos achados.

Além dos trabalhos que trazem, em seus próprios títulos e/ou resumos, a caracterização das condições de trabalho e saúde dos professores como objeto central (caso, por exemplo, do estudo de Gasparini et al., 2005), foram encontradas pesquisas que, embora investiguem objetos distintos, demonstram estar voltadas a elementos específicos do contexto de trabalho dos professores, cuja manifestação se vincula e/ou se explica diretamente a partir das condições laborais gerais. Tais estudos abordaram, por exemplo, assédio moral no trabalho (Campos et al., 2012); relação entre sindicalismo e configuração das condições de trabalho (Souza; Brito, 2012); e relação entre a implementação de inovações e a saúde (Friedman et al., 2013). Juntos, esses estudos formaram a primeira subcategoria "condições de trabalho e saúde em geral".

No mesmo sentido, estudos sobre o "perfil de morbidade dos professores" também foram vinculados à categoria em questão. É certo que tais pesquisas revelam doenças típicas como resultado principal. Por essa razão, chegamos a considerar inicialmente que deveriam entrar na lista da primeira categoria (conforme Tabela 1), a dos "problemas de saúde”. No entanto, após análise, constatamos que elas não se voltam a estudar, em particular, uma determinada doença ou problema de saúde típico, como é o caso dos trabalhos em questão.

Ao falarmos em condições de trabalho e saúde de determinado grupo profissional, o próprio assunto invoca naturalmente a necessidade de se conhecer o status de saúde do referido grupo, como os estudos sobre perfil de morbidade demonstram. De natureza quantitativa e caráter epidemiológico, esses trabalhos fornecem importante contribuição para a compreensão das condições de saúde da população estudada.

Dedicados à perspectiva da saúde ocupacional, contudo, as publicações fazem mais do que simplesmente traçar o perfil de morbidade de grupos profissionais. As condições de trabalho enfrentadas por tais grupos são colocadas em evidência, isto é, as circunstâncias que levaram, de modo direto ou indireto, ao quadro de saúde que descrevem. Por isso, como forma de explicar seus resultados, é comum que os estudos sobre o perfil de morbidade discutam o panorama das condições de trabalho que geraram as doenças ocupacionais por eles identificados, bem como a distribuição dessas doenças entre a população estudada.

Esses estudos, portanto, não apenas indicam a incidência e a prevalência de doenças entre uma população de trabalhadores, mas buscam também apresentar o contexto em que o adoecimento ocorreu, considerando as condições de trabalho existentes. Entendemos que dentro da categorização proposta, as características fundamentais desses estudos sobre perfil de morbidade corresponderam a categoria dos estudos sobre "condições de trabalho e saúde".

Embora saibamos que, em linhas gerais, todos os problemas de saúde dos professores (ao menos os decorrentes do trabalho), analisados sob a perspectiva da saúde do trabalhador, identifiquem essa interdependência entre condições de trabalho e saúde, referimo-nos, na segunda subcategoria (perfil de morbidade), a estudos cujo fenômeno central abordado (adoecimento) se manifesta de modo tão intimamente ligado às condições gerais de trabalho dos professores que as características e os componentes de tais condições se tornaram os elementos explicativos centrais.

Além das duas subcategorias supramencionadas, identificamos outras dedicadas a assuntos específicos, mas igualmente voltadas a eventos relacionados às condições de trabalho e saúde. Esse foi o caso dos estudos sobre "estratégias de resistência e promoção da saúde", "relações de gênero e trabalho", "pesquisa-intervenção" e "condições e agentes ambientais de risco", conforme Tabela 1. Todos esses estudos, de um modo ou de outro, demonstraram ter tomado as condições de trabalho e saúde como ponto de partida e/ou parâmetro central.

Reconhecendo a profusão de assuntos agrupados sob a categoria "condições de trabalho e saúde", bem como as diferenças existentes entre eles, consideramos a investida como complexa, porém proveitosa. Entendendo que a categorização de alguns trabalhos ocorreu em limites muito tênues, inserimos os critérios utilizados a serviço da sintetização, tentando garantir que as especificidades identitárias de cada estudo fossem mantidas, o que foi possível expressar a partir dos próprios títulos das subcategorias. 
Do ponto de vista metodológico, com exceção dos artigos sobre perfil de morbidade e dos poucos estudos sobre análise ambiental de agentes de riscos (identificados com a área de higiene ocupacional), a maior parte dos achados da seção empregou método qualitativo, baseando-se em entrevistas ou na observação da atividade de trabalho. Psicodinâmica do trabalho e ergonomia foram os principais referenciais teóricos, além da clínica da atividade e da ergologia, em menor expressão.

\section{Categoria 3. Estudos sobre qualidade de vida $e$ trabalho de professores}

A análise da produção acadêmica sobre trabalho e saúde dos professores também revelou um conjunto expressivo de estudos relativos à qualidade de vida dos docentes. De modo peculiar, tais estudos se mostraram apenas a partir do ano de 2006, revelando-se constantes desde então e apontando para um interesse crescente pelo assunto, conforme mostra o Gráfico 2.

Entre os achados dessa categoria, dois grupos principais se destacaram. O primeiro trata da qualidade de vida de professores no sentido estrito do trabalho, sendo caracterizado por estudos sobre qualidade de vida no trabalho (QVT). O outro se constituiu de publicações voltadas a estudar a qualidade de vida de professores em sentido específico, isto é, relacionada a algum problema de saúde como distúrbio vocal ou esgotamento profissional (Burnout), por exemplo.

O objetivo principal do conjunto de estudos sobre qualidade de vida foi identificar (mensurar, mais precisamente) o status da qualidade de vida dos professores, seja em sentido amplo ou relacionado a alguma patologia específica, conforme apresentado. A abordagem de natureza tipicamente quantitativa e o uso de instrumentos predominantemente padronizados estão entre as características principais desses estudos.

Com relação aos instrumentos, os achados apontaram para a existência de, igualmente, dois tipos: os genéricos e os específicos. De acordo com Dantas et al. (2003), os instrumentos genéricos podem ser usados para estudar indivíduos da população geral ou grupos específicos (como professores), tendo a vantagem de permitir comparar a qualidade de vida de indivíduos sadios com doentes ou de portadores da mesma doença. Como desvantagem, não são sensíveis à detecção de aspectos particulares e específicos da qualidade de vida de indivíduos com uma determinada doença. Os instrumentos específicos, por sua vez, teriam, segundo as autoras, a vantagem de conseguir detectar tais particularidades da qualidade de vida em determinadas situações, a despeito de suas dificuldades na compreensão do fenômeno e na validação das características psicométricas do instrumento. Por fornecerem informações diferentes (e, portanto, complementares), tais instrumentos podem, segundo elas, serem usados concomitantemente.

Entre os instrumentos de tipo genérico mais utilizados nos estudos sobre qualidade de vida dos professores, dois se destacaram. 0 primeiro foi o Medical Outcomes Studies 36-item Short-Form (MOS SF-36), que analisa, basicamente, oito domínios: capacidade funcional; limitações por aspectos físicos; dor; estado geral de saúde; vitalidade; aspectos sociais; limitação por aspectos emocionais e saúde mental, conforme, por exemplo, empregado no estudo de Rocha e Fernandes (2008). O outro é o World Health Organization Quality of Life/Bref (WHOQOL/breve ou WHOQOL-bref), instrumento validado pela Organização Mundial da Saúde (OMS). Esse instrumento (questionário) se propõe a mensurar a qualidade de vida a partir de quatro domínios: físico; psicológico; relações sociais; ambiente. Além desses quatro domínios, inclui duas questões sobre a percepção geral de qualidade de vida e saúde do indivíduo, conforme, por exemplo, empregado no estudo de Pereira et al. (2013).

Do ponto de vista dos estudos que utilizaram instrumentos específicos, a variedade de patologias abrangidas por eles levou a outro tipo de dinâmica marcada pelo uso de uma diversidade de ferramentas distintas. Recorrendo geralmente a algum instrumento genérico em caráter complementar, os recursos de análise utilizados por esses estudos se mostraram tão variados quanto o caso da patologia ou condição de saúde específica que busca investigar. Esse é o caso, por exemplo, do instrumento Qualidade de Vida em Voz (QVV), identificado, por Ribas et al. (2014), como a ferramenta mais utilizada, assim como 
o Maslach Burnout Inventory (MBI), utilizado por Tabeleão et al. (2011) em seu estudo sobre qualidade de vida e esgotamento profissional de professores.

De modo geral, os achados da categoria "qualidade de vida e trabalho" também envolveram, ainda que em menor expressão, estudos sobre bemestar e satisfação e estilo de vida de professores.

Em seu conjunto, os resultados indicaram, curiosamente, níveis relativamente altos de satisfação com a qualidade de vida entre os professores, ao mesmo tempo em que, em sentido oposto, altos níveis de insatisfação com o trabalho (Moreira et al., 2010; Penteado; Pereira, 2007; Oliveira et al., 2016).

\section{Categoria 4. Estudos sobre trabalho, carreira $e$ fundamentos da ação docente}

Os resultados vinculados a esta seção possuem uma peculiaridade notável: surgiram apenas na pesquisa junto à base SciELO. Isso se explica tanto pela origem de tais estudos, quanto pela natureza distinta das duas bases consultadas. Enquanto a BVS se dedica especificamente ao campo da saúde, a SciELO possui um espectro de indexação mais abrangente, contemplando periódicos de diversos campos do saber.

Oriundos, sobretudo, do campo da educação (pedagogia e psicologia educacional, além de estudos do campo da economia, abordando salário e carreira docente) e marcados pela abordagem quase exclusivamente qualitativa, os achados ancorados nessa categoria foram os mais complexos de tipificar, já que seus títulos, assuntos e formas de apresentação manifestaram ampla diversidade, conforme a Tabela 1 demonstra. Recorrendo a um estilo mais livre e, por vezes, até poético, como é habitual em alguns campos como o educacional, tais estudos, muitas vezes, se utilizaram de títulos e apresentações que nem sempre correspondiam propriamente a seus reais objetos de pesquisa. Feita a análise completa do material, constatou-se que alguns títulos, aparentemente muito distintos entre si, tratavam do mesmo assunto.

De modo geral, o conjunto desses achados refletiu duas grandes linhas de pesquisa: formação de professores e políticas públicas educacionais. Foi observado que, dentre os 35 trabalhos analisados nessa categoria, nenhum se ocupou propriamente das questões de saúde dos professores. Isso indica, preliminarmente, que os estudos da área de educação não têm se ocupado em pesquisar a saúde de seus profissionais, quer na perspectiva da formação dos professores ou das políticas públicas educacionais. Mesmo quando o tema "trabalho docente" foi evocado, a preocupação concentrou-se em questões pedagógicas e/ou da carreira, visando discutir como o trabalho docente pode ser melhorado em termos de resultados pedagógicos, não de saúde.

\section{Tabela I - Composição das publicações - categorias e subcategorias}

\begin{tabular}{|c|c|c|}
\hline \multirow{2}{*}{ Categorias e subcategorias } & \multicolumn{2}{|c|}{ Publicações } \\
\hline & $\mathrm{N}$ & $\%$ \\
\hline I. Problemas de saúde & 73 & 42 \\
\hline Saúde vocal/distúrbios da voz & 46 & 63 \\
\hline $\begin{array}{l}\text { Saúde mental/Transtornos mentais e } \\
\text { comportamentais }\end{array}$ & 23 & 32 \\
\hline Transtornos musculoesqueléticos & 2 & 3 \\
\hline Saúde cardiovascular & I & 1 \\
\hline Saúde ocular & I & 1 \\
\hline 2. Condições de trabalho e saúde & 38 & 22 \\
\hline Condições de trabalho e saúde em geral & 17 & 45 \\
\hline Perfil de morbidade & II & 29 \\
\hline Estratégias de resistência e produção de saúde & 3 & 8 \\
\hline Relações de gênero & 3 & 8 \\
\hline Pesquisa-intervenção & 2 & 5 \\
\hline Condições e agentes ambientais de risco & 2 & 5 \\
\hline 3. Qualidade de vida & 29 & 16 \\
\hline $\begin{array}{l}\text { Qualidade de vida stricto sensu (ou QV } \\
\text { relacionada ao trabalho) }\end{array}$ & 12 & 41 \\
\hline $\begin{array}{l}\text { Qualidade de vida associada a problemas de } \\
\text { saúde típicos }\end{array}$ & 10 & 35 \\
\hline Bem-estar/Satisfação & 4 & 14 \\
\hline Estilo de vida & 3 & 10 \\
\hline $\begin{array}{l}\text { 4. Trabalho, carreira e fundamentos da } \\
\text { ação docente }\end{array}$ & 35 & 20 \\
\hline Identidade e trabalho docente & 13 & 37 \\
\hline $\begin{array}{l}\text { Vida funcional docente: salário, valorização } \\
\text { e carreira }\end{array}$ & 9 & 26 \\
\hline Modelos, princípios e dinâmicas formativas & 5 & 14 \\
\hline
\end{tabular}




\section{Tabela I - Continuação}

\begin{tabular}{lcc} 
& \multicolumn{2}{c}{ Publicações } \\
\cline { 2 - 3 } Categorias e subcategorias & $\mathrm{N}$ & $\%$ \\
$\begin{array}{l}\text { Políticas de avaliação e organização do } \\
\text { trabalho docente }\end{array}$ & 3 & 9 \\
Abandono/permanência na carreira & 4 & 11 \\
Intervenção (formativa) & 1 & 3 \\
Total geral & 175 & 100 \\
\hline
\end{tabular}

Fonte: Elaboração própria com referência aos dados do levantamento junto à BVS e SCIELO

\section{Distribuição dos resultados segundo o ano de publicação}

A análise dos estudos segundo o ano de publicação revelou que, a despeito de algumas flutuações, houve aumento do interesse pelo tema, especialmente a partir de 2006. Foram 38 estudos entre 1997 e 2006 (média de 3,8 publicações), período contemplado pelo estudo de referência (Leite; Souza, 2011) e 137 novos estudos desde então, isto é, entre 2007 e 2017 (média de 12.4). 0 Gráfico 2 apresenta tais resultados.

Considerando o estudo de Leite e Souza (2011), cabe explicitar que os 38 resultados que identificamos no mesmo período (1997-2006) não se confundem com as 65 obras descritas naquele trabalho, visto que identificamos apenas nove artigos como diretamente decorrentes das teses ou dissertações analisadas por aquela obra. Assim, estamos nos referindo a um conjunto de pelo menos 240 publicações (este levantamento $n=175$, estudo supramencionado $n=65$ ).

\section{Gráfico 2 - Conjunto de resultados segundo o ano de publicação}

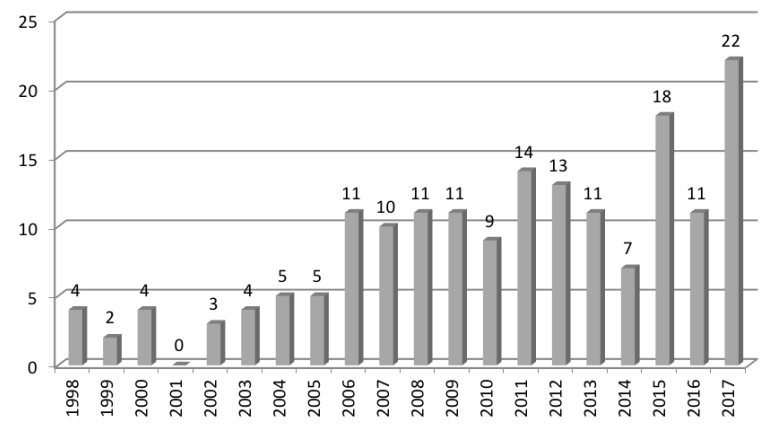

Observação: não houve resultados para o ano de 1997.

Fonte: Elaboração própria com referência aos dados do levantamento junto à BVS e SCIELO

\section{Discussão}

Além de apresentar o perfil das publicações, objetivo inicial de nosso trabalho, encontramos resultados semelhantes aos do estudo de revisão que tomamos por base (Leite; Souza, 2011), confirmando a permanência de um panorama de intensificação da precariedade e do adoecimento entre os professores.

Nesse sentido, as autoras verificaram o predomínio de pesquisas sobre agravos mentais e vocais em professores, afirmando que: "as principais situações mórbidas a atingir os professores têm sido disfunções vocais, estresse, depressões entre outras" (Leite; Souza, 2011, p.1110). Em termos das morbidades mais prevalentes, os estudos produzidos desde então confirmam os resultados obtidos nas pesquisas anteriores. Em termos do perfil das publicações, os estudos sobre problemas específicos de saúde continuam sendo maioria, constituindo $42 \%$ dos nossos achados.

Com relação aos novos elementos identificados, além do próprio aumento do volume das publicações, destacaram-se também a emergência de estudos sobre qualidade de vida relacionada ao trabalho dos professores a partir de 2006 e, conforme buscamos incorporar, a ampliação do olhar para os estudos sobre trabalho docente conduzidos pelo campo da educação, algo que constituiu uma categoria específica em nosso perfil, embora o critério de classificação não tenha sido definido por área do conhecimento, e sim por objeto de estudo.

Estudos de revisão de literatura têm o potencial de auxiliar pesquisadores e demais interessados a se situarem diante de problemas e contextos de pesquisa afins. Critérios distintos de busca e classificação dos achados podem ser empregados, visto que todos pressupõem certo nível de arbitrariedade, como lembra Paparelli (2009), repercutindo escolhas e variações. Ainda assim, seja qual for o critério adotado, tais estudos se mostram relevantes principalmente diante de assuntos cujo acúmulo de obras alcança um volume significativo e demanda algum tipo de síntese, como é o caso do tema estudado neste trabalho. Ao fazê-lo, os pesquisadores reorganizam o próprio estado da arte do assunto e fornecem um ponto de partida praticável.

0 estudo de Cunha (2009), por exemplo, dedicouse a analisar a produção científica no Brasil sobre 
síndrome de Burnout e docência, entre os anos de 2003 e 2008. A autora identificou uma variedade de obras e, focalizando a questão específica do Burnout, propôs uma categorização baseada nos seguintes critérios: (1) Discriminação por periódicos, áreas de concentração e ano de publicação; (2) Metodologias utilizadas nos estudos; (3) Distribuição das obras segundo a região de publicação.

Por ser específico sobre Burnout, o conjunto de obras com os quais o estudo lidou foi numericamente restrito $(n=10)$, mas chamou a atenção para a percepção de que categorizar essas obras (segundo critérios próprios, conforme os objetivos do estudo) seria oportuno.

O estudo de Cortez et al. (2017) incluiu uma proposta semelhante. Os autores se propuseram a analisar publicações da Biblioteca Virtual de Saúde em Psicologia (BVS-Psi) relacionadas à saúde no trabalho docente, de modo a cobrir um período de 14 anos (2003-2016). Embora tenham mencionado se tratar de levantamento especificamente voltado à área de psicologia, os resultados apresentados não se limitaram a tal, contemplando estudos de diversas áreas, como: fonoaudiologia, pedagogia, medicina, administração, enfermagem, entre outras. Englobaram também professores dos mais variados níveis (da educação infantil ao superior), sem considerar as especificidades de cada um, o que entendemos demandar certa cautela, ao menos quando se trata de analisar tais dados em conjunto, como se fez no estudo em questão.

Em termos de volume das publicações, os resultados que encontraram $(n=69)$ foram próximos aos que também encontramos na BVS ( $\mathrm{n}=101)$, indicando que, a despeito do anunciado pelos autores, sua busca parece mesmo não ter retornado apenas resultados do campo da psicologia (BVS-Psi). Assim, a diferença deveu-se, sobretudo, ao recorte temporal empreendido (2003-2016). O principal fato a destacar, contudo, é que o trabalho supramencionado apresentou a mesma preocupação em propor uma categorização das obras, conforme argumentamos. Sendo um estudo típico de revisão, seus critérios de classificação foram diversos, englobando: área; referencial teórico; tema; participantes; método; instrumentos; eixos de análise e agrupamentos de temas predominantes.

Por terem também apresentado uma forma própria de categorização dos seus achados, cabe retomar aqui o diálogo com o trabalho de Leite e Souza (2011) que se propuseram a analisar as obras identificadas "a partir das pesquisas sobre o malestar docente, estresse emocional e síndrome de Burnout" (Leite; Souza, 2011, p. 1110). No documento eletrônico "Estado da arte" (Leite; Souza, 2007), os resultados foram apresentados e discutidos a partir das categorias: "1. 0 trabalho docente em números; 2. Organização do trabalho docente: condições de trabalho e saúde; 3. Mal-estar docente; 4. Estudos sobre a voz: distúrbios vocais; 5 . Estresse Emocional e Síndrome de Burnout" (Leite; Souza, 2007, p. 19). É perceptível que a tendência seguida pelas autoras foi a de classificar as obras segundo o objeto de investigação de cada estudo (Burnout, mal-estar, disfonia etc.), conforme também priorizamos.

Considerando o Estado da arte (Leite; Souza, 2011) como uma importante contribuição para a área e baseando-se nele, Paparelli (2009) também propôs uma reclassificação para os achados, sendo: (1) Pesquisas do campo da Fonoaudiologia; (2) Perfil epidemiológico de morbidade dos docentes; (3) Pesquisas que analisam o sofrimento mental, como Burnout ou estresse; (4) Pesquisas que analisam sofrimento mental em geral; (5) Pesquisas em ergonomia da atividade e psicodinâmica do trabalho; e (6) Temas diversos ou grupo de trabalhos que não se enquadraram em nenhuma das categorias construídas. Como se observa, o critério adotado foi híbrido, contemplando tanto objetos de pesquisa (por exemplo: "pesquisas que analisam sofrimento mental”), quanto campos de estudo ("Pesquisas do campo da fonoaudiologia", "Pesquisas em ergonomia da atividade").

Ao percebermos certos padrões nos trabalhos investigados, entendemos que, a exemplo das outras obras consultadas, seria oportuno propor agrupá-los por categorias. O fato de termos encontrado um número expressivo de publicações também confirmou a viabilidade do intento, já que ao trabalharmos com um determinado volume de publicações, a busca por alguma estratégia capaz de organizar e consolidar os dados encontrados parece se tornar indispensável.

Por fim, conforme as publicações mencionadas nesta discussão permitem perceber, alguns trabalhos apresentaram características de estudos de revisão, seguindo duas tendências principais. A primeira 
foi a de perspectiva mais ampla, isto é, a de revisão geral sobre o tema trabalho e saúde dos professores. Os estudos de Leite e Souza (2011) e de Cortez et al. (2017) representaram essa tendência

A segunda tendência foi a de revisões focadas em assuntos específicos, tais como Burnout (Cunha, 2009; Carlotto; Câmara, 2008), qualidade de vida (Dantas et al., 2003; Pereira et al., 2009) e qualidade de vida relacionada à voz de professores (Ribas et al., 2014).

De acordo com os critérios adotados para mapear e organizar nossos achados (focados nos objetos das pesquisas), o primeiro tipo de estudo mencionado (revisão geral) foi categorizado em "condições de trabalho e saúde", já os trabalhos do segundo tipo foram inseridos nas categorias/subcategorias mais correlatas ao assunto específico de cada revisão. Por exemplo, estudos de revisão sobre Burnout foram categorizados junto à categoria "problemas de saúde", subcategoria "saúde mental".

A esse respeito, cabe explicitar que, em termos de referencial teórico, os estudos encontrados sobre saúde mental dos professores se ancoram predominantemente naquilo que Paparelli (2009, p. 38-39) chamou de "teoria do estresse", perspectiva que inclui a síndrome de Burnout, assunto principal entre os achados da subcategoria em questão. Embora não negue a existência do problema nem a importância de seu reconhecimento enquanto doença relacionada ao trabalho, a autora enfatiza que o modo de explicar o processo de adoecimento presente na teoria do Burnout incorre em reducionismos, quais sejam: a não incorporação dos avanços trazidos pela perspectiva da saúde do trabalhador; a concepção de adoecimento ocupacional calcada em matriz culpabilizante, que naturaliza os agentes estressores e culpabiliza o próprio indivíduo por não conseguir enfrentá-los; e a verve adaptacionista, entendimento de que o trabalhador precisa dispor dos recursos pessoais necessários ao enfrentamento e superação das nocividades do trabalho. Assim, propõe o conceito de desgaste mental.

Do mesmo modo, os estudos identificados sob a categoria "qualidade de vida" também ensejam reflexões quanto às fragilidades de tal concepção para a apreensão da relação saúde-trabalho. Isso, sobretudo, porque o pressuposto individualizante subjacente a tal abordagem que é marcado, entre outros, por ações pessoais como mudanças cognitivas e comportamentais, não atinge a esfera da organização do trabalho, categoria de análise fundamental para explicar os problemas de saúde dos trabalhadores (Paparelli, 2009).

\section{Considerações finais}

Mais do que descrever os achados de nossa pesquisa, o perfil das publicações que se apresenta é uma proposta de fornecer aporte para os trabalhos de mapeamento, análise e discussão dos estudos sobre condições de trabalho e saúde dos professores. Não se destina, portanto, à mera descrição, mas à proposição de um parâmetro que possa ser incorporado ao trabalho de reconhecimento e análise da literatura dedicada ao assunto.

Mesmo considerando suas limitações, como a de termos contemplado fundamentalmente estudos com professores brasileiros, as categorias e subcategorias apresentadas (e, dentro delas, as próprias publicações que as compõem) têm o potencial de serem, ao mesmo tempo, organizativas e expansivas. Como estruturas de organização, cada categoria e subcategoria pode ser pensada como um ancoradouro para a acomodação e discussão de estudos atuais e futuros.

Por constituir uma dentre tantas possibilidades organizativas, as pesquisas permitem redimensionamentos, já que não são estanques. Fornecem, principalmente, um mapeamento, indicando aquilo que se tem publicado e o que, por ausência ou fragilidade demonstrada, requer aprofundamento. Ao fazê-lo, oferecem pistas sobre novas estruturas ou categorias de trabalho que eventualmente se mostrarem relevantes para ampliar ou reconfigurar tal perfil.

Caso, por exemplo, a busca dos artigos estivesse incluindo o momento atual, o perfil das publicações certamente teria que incluir novo tema de estudo: o da relação entre o trabalho e a saúde de professores durante a pandemia de covid-19. Restaria discutir em qual de suas categorias/subcategorias seria inserido ou se inauguraria uma nova.

Em termos de resultados principais, constatou-se que, o número de publicações vem crescendo desde a última revisão de literatura de cunho mais amplo sobre o assunto e que o interesse pelo tema "qualidade de vida dos professores" emergiu a partir de 2006. Concluiuse também que os estudos do campo educacional não 
têm inserido a preocupação com a temática da saúde dos professores mesmo quando o intuito é estudar o trabalho docente, a formação de professores e as políticas públicas educacionais. A aproximação dos campos torna-se fundamental, bem como a adoção de ações de intervenção, já que, a despeito do significativo número de estudos publicados, pouco se tem feito em termos de ações práticas ancoradas nos resultados desses estudos para a melhoria das condições de trabalho e saúde dos professores.

\section{Referências}

ARAÚJO, T. M.; PINHO, P. S.; MASSON, M. L. V. Trabalho e saúde de professoras e professores no Brasil: reflexões sobre trajetórias das investigações, avanços e desafios. Cadernos de Saúde Pública, Rio de Janeiro, v. 35, n. 1, p. 1-14, 2019. DOI: 10.1590/0102-311X00087318

ASSUNÇÃO, A. Á.; OLIVIERA, D. A. Intensificação do trabalho e saúde dos professores. Educação e Sociedade, Campinas, v. 30, n. 107, p. 349-372, 2009. DOI: 10.1590/So101-73302009000200003

CAMPOS, I. C. M., SERAFIM, A. C., CUSTÓDIO, K. V. et al. Moral harassment of public schools teachers. Work, Amsterdam, v. 41, n. 1, p. 20012007, 2012. DOI: 10.3233/WOR-2012-0422-2001

CARLOTTO, M. S.; CÂMARA, S. G. Análise da produção científica sobre a Síndrome de Burnout no Brasil. Psico, Porto Alegre, v. 39, n. 2, p. 152-158, 2008. Disponível em: <https://revistaseletronicas. pucrs.br/ojs/index.php/revistapsico/article/ view/1461/3035>. Acesso em: 20 jul. 2021.

CORTEZ, P. A.; SOUZA, M. V. R.; AMARAL, L. O. et al. A saúde docente no trabalho: apontamentos a partir da literatura recente. Cadernos de Saúde Coletiva, Rio de Janeiro, v. 25, n. 1, p. 113-122, 2017. DOI: 10.1590/1414-462X201700010001

CUNHA, K. W. V. A produção científica no Brasil nos anos de 2003 a 2008 sobre síndrome de Burnout e docência. 2009. Tese (Mestrado em Saúde Pública) - Escola Nacional de Saúde Pública Sergio Arouca, Fiocruz, Rio de Janeiro, 2009. Disponível em: <https://www.arca.fiocruz.br/ handle/icict/2352>. Acesso em: 20 jul. 2021.
DANTAS, R. A. S.; SAWADA, N. O.; MALERBO, M. B. Pesquisas sobre qualidade de vida: revisão da produção científica das universidades públicas do estado de São Paulo. Latino-americana Enfermagem, Ribeirão Preto, v. 11, n. 4, p. 532-538, 2003. DOI: 10.1590/So104-11692003000400017

DELCOR, N. S.; ARAÚJO, T. M.; REIS, E. J. F. B. et al. Condições de trabalho e saúde dos professores da rede particular de ensino de Vitória da Conquista, Bahia, Brasil. Cadernos de Saúde Pública, Rio de Janeiro, v. 2o, n. 1, p. 187-196, 2004. DOI: 10.1590/So102-311X2004000100035

FARBER, B. A. Teacher Burnout: assumptions, myths, and issues. Eric, Chicago, p. 1-30, 1982. Disponível em: <https://eric. ed.gov/?id=ED229369>. Acesso em: 20 jul. 2021.

FERREIRA, L. L. Relação entre o trabalho e a saúde de professores na Educação Básica no Brasil. Relatório Final do Projeto “Condições de trabalho e suas repercussões na saúde dos professores de Educação Básica no Brasil”. São Paulo: Fundacentro, 2010.

FRIEDMAN, S. R.; LOH, L. C.; BURDICK, W. P. Educator perceptions of the relationship between education innovations and improved health. Medical Teacher, London, v. 35, n. 4, p. 106o-1067, 2013. DOI: 10.3109/0142159X.2012.733450

GASPARINI, S. M.; BARRETO, S. M.; ASSUNÇÃO, A. Á. O professor, as condições de trabalho e os efeitos sobre sua saúde. Educação e Pesquisa, São Paulo, v. 31, n. 2, p. 189-199, 2005. DOI: 10.1590/S1517-97022005000200003

GIBBS, G. Análise de dados qualitativos. Porto Alegre: Artmed, 2009.

GUERREIRO, N. P.; NUNES, E. F. P. A.; GONZÁLEZ, A. D. et al. Perfil sociodemográfico, condições e cargas de trabalho de professores da rede estadual de ensino de um município da região sul do Brasil. Trabalho, Educação e Saúde, Rio de Janeiro, v. 14, n. 1, p. 197-217, 2016. DOI: 10.1590/1981-7746-solooo27

LEITE, M. P.; SOUZA, A. N. (Coord.). Condições de trabalho e suas repercussões na saúde de professores da educação básica no Brasil: estado da arte. Campinas: Unicamp, 2007. 
LEITE, M. P.; SOUZA, A. N. Condições de trabalho e suas repercussões na saúde de professores da educação básica no Brasil. Educação e Sociedade, Campinas, v. 32, n. 117, p. 1105-1121, 2011. DOI: 10.1590/So101-73302011000400012

MENDES, R.; DIAS, E. C. Da medicina do trabalho à saúde do trabalhador. Revista de Saúde Pública, São Paulo, v. 25, n. 5, p. 341-349, 1991. Disponível em: < https://www.nescon.medicina.ufmg.br/biblioteca/ imagem/2977.pdf >. Acesso em: 20 jul. 2021.

MOREIRA, H. R.; NASCIMENTO, J. V.; SONOO, C. N. et al. Qualidade de vida do trabalhador docente e os ciclos vitais de professores de educação física do estado do Paraná, Brasil. Revista brasileira de ciência e movimento, Brasília, DF, v. 18, n. 3, p. 122O, 2010. DOI: 10.18511/rbcm.v18i3.1650

OLIVEIRA, T. F.; LINS, V. L.; SILVA, R. M. et al. Qualidade de vida no trabalho: um estudo comparativo entre professores de escola pública e privada.

Psicologia Argumento, Curitiba, v. 34, n. 85, p. 104-119, 2016. DOI: 10.7213/psicol.argum.34.085.AOo2

PAPARELLI, R. Desgaste mental do professor da rede pública de ensino: trabalho sem sentido sob a política de regularização de fluxo escolar. Tese (Doutorado em Psicologia) - Instituto de Psicologia, Universidade de São Paulo, São Paulo, 2009. Disponível em : <https://www.teses.usp.br/ teses/disponiveis/47/47134/tde-071220o9-145916/ pt-br.php>. Acesso em: 20 jul. 2021.

PENTEADO, R. Z.; PEREIRA, I. M. T. B. Qualidade de vida e saúde vocal de professores. Revista de Saúde Pública, São Paulo, v. 41, n. 2, p. 236-243, 2007. DOI: 10.1590/So034-89102007000200010 PEREIRA, É. F.; TEIXEIRA, C. S.; SANTOS, A. et al. Qualidade de vida e saúde dos professores de educação básica: discussão do tema e revisão de investigações. Revista Brasileira de Ciência e Movimento, Brasília, DF, v. 17, n. 2, p. 100-107, 2009. DOI: 10.18511/rbcm.v17i2.1035

PEREIRA, É. F.; TEIXEIRA, C. S.; LOPES, A. S. Qualidade de vida de professores de educação básica do município de Florianópolis, SC, Brasil. Ciência e Saúde Coletiva, Rio de Janeiro, v. 18, n. 7, p. 1963-1970, 2013. DOI: 10.1590/S141381232013000700011

RIBAS, T. M.; PENTEADO, R. Z.; GARCÍA-ZAPATA, M. T. A. Qualidade de vida relacionada à voz de professores: uma revisão sistemática exploratória da literatura. $C E F A C$, Campinas, v. 16, n. 1, p. 294-306, 2014. DOI: 10.1590/1982-021620144812

ROCHA, V. M.; FERNANDES, M. H. Qualidade de vida de professores do ensino fundamental: uma perspectiva para a promoção da saúde do trabalhador. Jornal Brasileiro de Psiquiatria, Rio de Janeiro, v. 57, n. 1, p. 23-27, 2008. DOI: 10.1590/Soo47-20852008000100005

SILVA, J. P.; FISCHER, F. M. Invasão multiforme da vida pelo trabalho entre professores de educação básica e repercussões sobre a saúde. Revista de Saúde Pública, São Paulo, v. 54, n. 3, p. 1-8, 2020. DOI: $10.11606 / \mathrm{s} 1518-8787.2020054001547$

SOUZA, K. R.; BRITO, J. C. Sindicalismo, condições de trabalho e saúde: a perspectiva dos profissionais da educação do Rio de Janeiro. Ciência e saúde coletiva, Rio de Janeiro, v. 17, n. 2, p. 379-388, 2012. DOI: 10.1590/S1413-81232012000200012

TABELEÃO, V. P.; TOMASI, E.; NEVES, S. F. Qualidade de vida e esgotamento profissional entre docentes da rede pública de Ensino Médio e Fundamental no Sul do Brasil. Cadernos de Saúde Pública, Rio de Janeiro, v. 27, n. 12, p. 2401-2408, 2011. DOI: 10.1590/So102-311X2011001200011

THE ILO/UNESCO Recommendation concerning the Status of Teachers (1966) and the UNESCO Recommendation concerning the Status of Higher-Education Teaching Personnel (1997). Geneva, ILO, 2016.

VEDOVATO, T. G.; MONTEIRO, M. I. Perfil sociodemográfico e condições de saúde e trabalho dos professores de nove escolas estaduais paulistas. Escola de Enfermagem, São Paulo, v. 42, n. 2, p. 290-297, 2008. DOI: 10.1590/Soo8o62342008000200012

\section{Contribuição dos autores}

Silva foi responsável pela concepção, planejamento, desenho e execução do estudo, coleta, análise e discussão dos dados e elaboração do manuscrito.

Fischer foi responsável pelo planejamento e desenho do estudo, pelas sugestões das análises, discussão dos dados, revisão crítica das várias versões do artigo e aprovação da versão final.

Recebido: 07/05/2021

Aprovado: 06/07/2021 